\title{
Álcool \& Esporte: quais os impactos?
}

- Álcool antes do exercício não promove mudanças na performance e alguns estudos demonstraram um efeito negativo, como diminuição da carga de trabalho total e aumento do tempo em provas de 200 a 1500 metros;

- Embora alguns atletas utilizem bebidas alcoólicas após o exercício para ajudar na reidratação, as evidências científicas mostram que apenas bebidas com baixo teor de álcool (0,5\%) e com adição de sódio podem ajudar nesse processo. Além disso, bebidas como cerveja a 4,6\% de álcool podem prejudicar a retenção hídrica e aumentar o tempo de reação;

- A ingestão de álcool prejudica a ressíntese de glicogênio tanto em modelo animal quanto em humanos. O consumo de grandes quantidades de álcool após um exercício prolongado foi associado com prejuízos no metabolismo de carboidratos e lipídios. A associação do álcool com carboidrato e com maior tempo de recuperação minimiza esse impacto na ressíntese de glicogênio;

- Álcool interfere em parâmetros hormonais, como aumento de adrenalina, cortisol, dopamina, estradiol e insulina. Além disso, foi demonstrada associação inversa entre o consumo de álcool e hormônios como GH, LH, melatonina, serotonina, testosterona e vasopressina;

- A ingestão de álcool prejudica a síntese proteica, inibindo vias metabólicas na sinalização da mTOR. Além disso, álcool favorece inflamação e estresse oxidativo, o que, por consequência, pode estimular vias catabólicas. Álcool prejudica a função mitocondrial e a proliferação e diferenciação de células satélites;

- Álcool prejudica a beta-oxidação de ácidos graxos, aumenta o apetite e interfere na qualidade das escolhas alimentares. Além disso, pode interferir na qualidade do sono, também importante para os atletas;

- O consumo de álcool não é uma boa opção para atletas e, caso o consumo aconteça, o ideal é buscar uma opção com baixo percentual de álcool. O consumo deve ser controlado, em pequenas doses e com opção de bebidas com teor reduzido de álcool.

\section{Referências bibliográficas}

1. BARNES, M.J. Alcohol: impact on sports performance and recovery in male athletes. Sports Med; 44(7): 909-919, 2014.

2. FLORES-SALAMANCA, R.; ARAGON-VARGAS, L.F. Postexercise rehydration with beer impairs fluid retention, reaction time, and balance. Appl Physiol Nutr Metab; 39(10): 1175-1181, 2014.

3. BURKE, L.M.; VAN LOON, L.J.C.; HAWLEY, J.A. Postexercise muscle glycogen resynthesis in humans. J Appl Physiol (1985); 122(5): 1055-1067, 2017.

4. PARR, E.B.; CAMERA, D.M.; ARETA, J.L. et al. Alcohol ingestion impairs maximal post-exercise rates of myofibrillar protein synthesis following a single bout of concurrent training. PLoS One; 9(2): e88384, 2014.

5. LANG, C.H.; FROST, R.A.; DESHPANDE, N. et al. Alcohol impairs leucine-mediated phosphorylation of 4E-BP1, S6K1, elF4G, and mTOR in skeletal muscle. Am J Physiol Endocrinol Metab; 285(6): E1205-1215, 2003. 